\title{
A Quantitative Investigation of the Time-varying Beta of the International CAPM: The Case of North American and European Equity Portfolios
}

\author{
Chikashi Tsuji \\ Professor, Faculty of Economics, Chuo University \\ 742-1 Higashinakano, Hachioji-shi, Tokyo 192-0393, Japan \\ E-mail: mail_sec_low@minos.ocn.ne.jp
}

Received: Feb. 15, 2017 Accepted: March 26, $2017 \quad$ Published: April 1, 2017

doi:10.5296/jmr.v9i2.10937ＵRL: https://doi.org/10.5296/jmr.v9i2.10937

\begin{abstract}
This paper investigates the time-invariant and the time-varying betas of the international capital asset pricing model (CAPM) for North American and European equity portfolio returns over the period from August 1, 1990 to June 30, 2016. Our quantitative examinations using the full vector-half $(\mathrm{VECH})$ model reveal the following interesting evidence. First, we find that (1) the time-invariant international CAPM beta value for North American equity portfolio returns and that for European equity portfolio returns, which are derived from the standard ordinary least squares (OLS) method, are both close to one. In contrast, our examinations find that (2) the time-varying international CAPM betas of North American equity portfolio returns are lower than one before 1996, and slightly higher than one after around 1996. Moreover, our investigations further reveal that (3) the time-varying international CAPM betas of European equity portfolio returns are lower than one before around 2004, and clearly higher than one after around 2004.
\end{abstract}

Keywords: Asset pricing, European stock markets, International CAPM, North American stock markets, Time-varying beta 


\section{Introduction}

The beta values in asset pricing models are highly crucial for evaluating the evolution and relations of asset returns. In a globalizing economy, the dynamic evolution of the time-varying betas in the international capital asset pricing model (CAPM) is much meaningful for paying attention (Regarding the international CAPM, see Solnik (1974) and Stulz (1981) for example.). Based on this viewpoint, this paper examines both the time-invariant and the time-varying betas of the international CAPM for North American and European equity portfolio returns over the period from August 1, 1990 to June 30, 2016.

Our quantitative investigations using the full vector-half $(\mathrm{VECH})$ model (Bollerslev et al., 1988) reveal the following useful evidence. First, we clarify that (1) the time-invariant international CAPM beta value for North American equity portfolio returns and that for European equity portfolio returns, which are obtained from the standard ordinary least squares (OLS) method, are both close to one. Contrary, our further examinations reveal that (2) the time-varying international CAPM betas of North American equity portfolio returns are lower than one before 1996, and slightly higher than one after around 1996. Moreover, our examinations further find that (3) the time-varying international CAPM betas of European equity portfolio returns are lower than one before around 2004, and after around 2004, they move with clearly higher values than one.

After this introduction, Section 2 conducts a review of related literature; Section 3 explains our data; and Section 4 documents our analyzing methods. Section 5 reports our results and in Section 6, we conclude the article.

\section{Literature review}

This section briefly reviews related previous studies. Thomas and Wickens (1993) estimated a range of monthly international CAPMs for the period from 1973 to 1987 . Their samples included the equity and bond data of Germany, Japan, the US, and the UK. Jan et al. (2000) examined the explanatory power of the conditional version of the international CAPM for the returns of Pacific Basin equity markets; and their results showed that most individual Pacific Basin markets were explained by the conditional international CAPMs.

Further, using the equity data of Japan, the US, and the UK, Zhang (2006) attempted to evaluate the cross-sectional pricing performances of the international CAPMs. This study suggested that when time-varying betas and risk premia are incorporated, most international CAPMs passed the Hansen and Jagannathan's (1997) tests. Jacobsen and Liu (2008) also tested the pricing of international CAPMs and found that global, local, and currency risks were priced and time-varying in Chinese stock markets.

Moreover, Balvers and Klein (2014) examined the international CAPMs, and according to this study, a GMM approach showed the good performances of their conditional models; on the other hand, they suggested that the unconditional international CAPMs were rejected. Moreover, Tsuji (2012) quantitatively examined the alphas for the Japanese stock portfolios in a standard asset pricing framework and reported some positive alphas in Japan. As above, it is understood that the previous studies of the international CAPM are not so many. 


\section{Data}

This section documents the data used for our investigations. This study uses three kinds of daily international portfolio returns. Specifically, we use (1) the global stock market return, which we denote GL; (2) the North American equity portfolio return, which we denote NAM; and (3) the European equity portfolio return, which we denote EUR. All data are time-series percentage returns in US dollars, and they are kindly supplied by Kenneth French. The sample period is from August 1, 1990 to June 30, 2016.

\section{Models and methods}

We next describe our models and methods for our analyses. The following model (1) is the international CAPM, which is used normally by applying a simple regression approach as the OLS method.

$$
R_{i, t}-R_{F, t}=\alpha_{i}+\beta_{i}\left(R_{W, t}-R_{F, t}\right)+\kappa_{i, t} .
$$

In the above model (1), $R_{i, t}$ denotes a portfolio return (This study uses NAM or EUR.); $R_{W, t}$ denotes the global stock market return (This study uses GL.); and $R_{F, t}$ denotes the risk-free rate. By regressing $R_{i, t}$ on $R_{W, t}$, we can derive the time-invariant betas of the international CAPM as the following equation (2):

$$
\beta_{i}=\sigma_{i, W} / \sigma_{W}^{2}
$$

In equation (2), the numerator of the right-hand side denotes the time-invariant covariance of a portfolio return (NAM or EUR here) and the global stock market return (GL here); and the denominator of the right-hand side denotes the time-invariant variance of the global stock market return. For deriving the time-varying betas, this study employs the following full VECH model (3):

$$
\operatorname{vech}\left(\mathbf{H}_{t}\right)=\mathbf{C}+\mathbf{B} \text { vech }\left(\mathbf{H}_{t-1}\right)+\mathbf{A} \operatorname{vech}\left(\mathbf{e}_{t-1} \mathbf{e}_{t-1}^{\prime}\right) \text {. }
$$

In our application of model (3), only constant terms are used as the explanatory variables in the mean equations of GL and NAM or GL and EUR. In addition, $\mathbf{H}$ denotes the matrix of the time-varying variances and covariance and e denotes the matrix of the residuals of the mean equations. Further, A, B, and $\mathbf{C}$ are coefficient matrices and vech $(\cdot)$ represents the vector-half operator.

$$
\beta_{i, t}=\sigma_{i, W, t} / \sigma_{W, t}^{2}
$$

In this study, using the estimated elements of $\mathbf{H}$, we derive the time-varying betas as shown in the above equation (4), where the numerator of the right-hand side denotes the time-varying covariance of the global stock market return (GL) and a portfolio return (NAM or EUR) and the denominator of the right-hand side denotes the time-varying variance of the global stock market return $(\mathrm{GL})$. 
Table 1. The OLS estimation results of the international CAPM for North American and European equity portfolios

Panel A. Results for North American equity portfolio returns

\begin{tabular}{lllll}
\hline Variables & Coefficient & Standard error & $t$-statistic & $p$-value \\
\hline Constant & $0.0108 * *$ & 0.0052 & 2.0621 & 0.0392 \\
GL & $1.0286 * * *$ & 0.0142 & 72.4789 & 0.0000 \\
\hline
\end{tabular}

Adjusted R-squared value

0.7266

Panel B. Results for European equity portfolio returns

\begin{tabular}{lllll}
\hline Variables & Coefficient & Standard error & $t$-statistic & $p$-value \\
\hline Constant & 0.0001 & 0.0059 & 0.0097 & 0.9922 \\
GL & $1.0603 * * *$ & 0.0149 & 71.0736 & 0.0000 \\
\hline
\end{tabular}

Adjusted R-squared value

0.6859

Notes: $* * *$ and $* *$ mean the statistical significance of the estimates at the $1 \%$ and $5 \%$ levels, respectively.

\section{Empirical results}

First, Table 1 shows the OLS estimation results of the international CAPM for NAM and EUR. Table 1 shows that two OLS regressions derive statistically significant time-invariant international CAPM betas for NAM and EUR; and two adjusted R-squared values are both high. The time-invariant international CAPM beta for NAM is 1.0286 and that for EUR is 1.0603. We thus understand that two beta values derived by the OLS method are close to one.

Next, estimation results of the full VECH models are shown in Table 2. We note that in this table, $\mathrm{C}(i, j)$ denotes the element in the $i$-th row and $j$-th column of the matrix $\mathbf{C}$; $\mathrm{A}(i, j)$ denotes the element in the $i$-th row and $j$-th column of the matrix $\mathbf{A}$; and $\mathrm{B}(i, j)$ means the element in the $i$-th row and $j$-th column of the matrix $\mathbf{B}$ in equation (3). Panel A of Table 2 shows the estimation results for GL and NAM; and Panel B of this table exhibits the results for GL and EUR. As shown in this table, both results in Panels A and B indicate that our full VECH models are well estimated by our maximum likelihood method.

Further, Figure 1 exhibits the dynamic evolution of the time-varying international CAPM betas of NAM (Panel A) and EUR (Panel B). Both series are derived by using equation (4) and these series are depicted for the period from August 1, 1990 to June 30, 2016. From the time-series evolution in Figure 1, we firstly understand that (1) the time-varying international CAPM betas of North American equity portfolio returns are lower than one before 1996, and slightly higher than one after around 1996. We also understand that from Figure 1, (2) the time-varying international CAPM betas of European equity portfolio returns move with lower values than one before around 2004, and they are clearly higher than one after around 2004. 
Table 2. Estimation results of the full VECH models for global stock market, North American, and European equity portfolio returns

Panel A. Results for global stock market and North American equity portfolio returns

Mean equations

\begin{tabular}{|c|c|c|c|c|}
\hline Variables & Coefficient & Standard error & $t$-statistic & $p$-value \\
\hline Constant (GL) & $0.0593 * * *$ & 0.0074 & 8.0446 & 0.0000 \\
\hline Constant (NAM) & $0.0712 * * *$ & 0.0084 & 8.4640 & 0.0000 \\
\hline \multicolumn{5}{|l|}{ Variance equations } \\
\hline Variables & Coefficient & Standard error & $t$-statistic & $p$-value \\
\hline $\mathrm{C}(1,1)$ & $0.0113 * * *$ & 0.0013 & 8.8357 & 0.0000 \\
\hline $\mathrm{C}(2,1)$ & $0.0126 * * *$ & 0.0014 & 9.0080 & 0.0000 \\
\hline$C(3,1)$ & $0.0188 * * *$ & 0.0020 & 9.3514 & 0.0000 \\
\hline $\mathrm{A}(1,1)$ & $0.0612 * * *$ & 0.0055 & 11.2082 & 0.0000 \\
\hline $\mathrm{A}(1,2)$ & $-0.0216^{* * *}$ & 0.0079 & -2.7420 & 0.0061 \\
\hline $\mathrm{A}(1,3)$ & $0.0427 * * *$ & 0.0048 & 8.8868 & 0.0000 \\
\hline $\mathrm{A}(2,1)$ & $0.0235^{* * *}$ & 0.0043 & 5.4599 & 0.0000 \\
\hline $\mathrm{A}(2,2)$ & $0.0176^{* *}$ & 0.0078 & 2.2682 & 0.0233 \\
\hline $\mathrm{A}(2,3)$ & $0.0442 * * *$ & 0.0029 & 15.1071 & 0.0000 \\
\hline $\mathrm{A}(3,1)$ & $0.0349 * * *$ & 0.0081 & 4.2882 & 0.0000 \\
\hline $\mathrm{A}(3,2)$ & $-0.0367 * * *$ & 0.0142 & -2.5779 & 0.0099 \\
\hline $\mathrm{A}(3,3)$ & $0.1069 * * *$ & 0.0054 & 19.8519 & 0.0000 \\
\hline $\mathrm{B}(1,1)$ & $0.9103 * * *$ & 0.0052 & 175.9695 & 0.0000 \\
\hline $\mathrm{B}(1,2)$ & $0.0428^{* * *}$ & 0.0043 & 9.8544 & 0.0000 \\
\hline $\mathrm{B}(1,3)$ & $-0.0474 * * *$ & 0.0043 & -11.1383 & 0.0000 \\
\hline $\mathrm{B}(2,1)$ & $-0.0439 * * *$ & 0.0014 & -30.8870 & 0.0000 \\
\hline $\mathrm{B}(2,2)$ & $0.9987 * * *$ & 0.0045 & 220.6159 & 0.0000 \\
\hline $\mathrm{B}(2,3)$ & $-0.0523 * * *$ & 0.0016 & -33.6877 & 0.0000 \\
\hline $\mathrm{B}(3,1)$ & $-0.0599 * * *$ & 0.0077 & -7.8069 & 0.0000 \\
\hline $\mathrm{B}(3,2)$ & $0.0853^{* * *}$ & 0.0170 & 5.0211 & 0.0000 \\
\hline $\mathrm{B}(3,3)$ & $0.8598 * * *$ & 0.0088 & 97.4505 & 0.0000 \\
\hline
\end{tabular}


Panel B. Results for global stock market and European equity portfolio returns

Mean equations

\begin{tabular}{|c|c|c|c|c|}
\hline Variables & Coefficient & Standard error & t-statistic & $p$-value \\
\hline Constant (GL) & $0.0575 * * *$ & 0.0078 & 7.3878 & 0.0000 \\
\hline Constant (EUR) & $0.0633 * * *$ & 0.0103 & 6.1652 & 0.0000 \\
\hline \multicolumn{5}{|c|}{ Variance equations } \\
\hline Variables & Coefficient & Standard error & $t$-statistic & $p$-value \\
\hline $\mathrm{C}(1,1)$ & $0.0056 * * *$ & 0.0017 & 3.2513 & 0.0011 \\
\hline $\mathrm{C}(2,1)$ & 0.0033 & 0.0021 & 1.5146 & 0.1299 \\
\hline $\mathrm{C}(3,1)$ & $0.0790 * * *$ & 0.0147 & 5.3724 & 0.0000 \\
\hline $\mathrm{A}(1,1)$ & $0.1000 * * *$ & 0.0163 & 6.1276 & 0.0000 \\
\hline $\mathrm{A}(1,2)$ & $-0.0844 * * *$ & 0.0218 & -3.8779 & 0.0001 \\
\hline $\mathrm{A}(1,3)$ & $0.0519 * * *$ & 0.0076 & 6.8232 & 0.0000 \\
\hline $\mathrm{A}(2,1)$ & $0.0526 * * *$ & 0.0141 & 3.7382 & 0.0002 \\
\hline $\mathrm{A}(2,2)$ & -0.0163 & 0.0195 & -0.8362 & 0.4031 \\
\hline $\mathrm{A}(2,3)$ & $0.0384 * * *$ & 0.0080 & 4.8203 & 0.0000 \\
\hline $\mathrm{A}(3,1)$ & $0.2338 * * *$ & 0.0240 & 9.7540 & 0.0000 \\
\hline $\mathrm{A}(3,2)$ & $-0.2752 * * *$ & 0.0343 & -8.0123 & 0.0000 \\
\hline $\mathrm{A}(3,3)$ & $0.1645 * * *$ & 0.0146 & 11.2324 & 0.0000 \\
\hline $\mathrm{B}(1,1)$ & $0.8827 * * *$ & 0.0215 & 41.1046 & 0.0000 \\
\hline $\mathrm{B}(1,2)$ & -0.0003 & 0.0179 & -0.0184 & 0.9853 \\
\hline $\mathrm{B}(1,3)$ & 0.0081 & 0.0054 & 1.4928 & 0.1355 \\
\hline $\mathrm{B}(2,1)$ & $-0.0559 * * *$ & 0.0189 & -2.9511 & 0.0032 \\
\hline $\mathrm{B}(2,2)$ & $0.8797 * * *$ & 0.0124 & 70.9375 & 0.0000 \\
\hline $\mathrm{B}(2,3)$ & $0.0483 * * *$ & 0.0092 & 5.2601 & 0.0000 \\
\hline $\mathrm{B}(3,1)$ & $-0.1221 *$ & 0.0720 & -1.6959 & 0.0899 \\
\hline $\mathrm{B}(3,2)$ & $1.2416 * * *$ & 0.2303 & 5.3900 & 0.0000 \\
\hline $\mathrm{B}(3,3)$ & 0.0887 & 0.1664 & 0.5328 & 0.5942 \\
\hline
\end{tabular}

Notes: This table presents the estimation results of the full VECH models. ***,**, * mean the statistical significance of the estimates at the $1 \%, 5 \%$, and $10 \%$ levels, respectively. 
Panel A. Time-varying betas of the North American equity portfolio

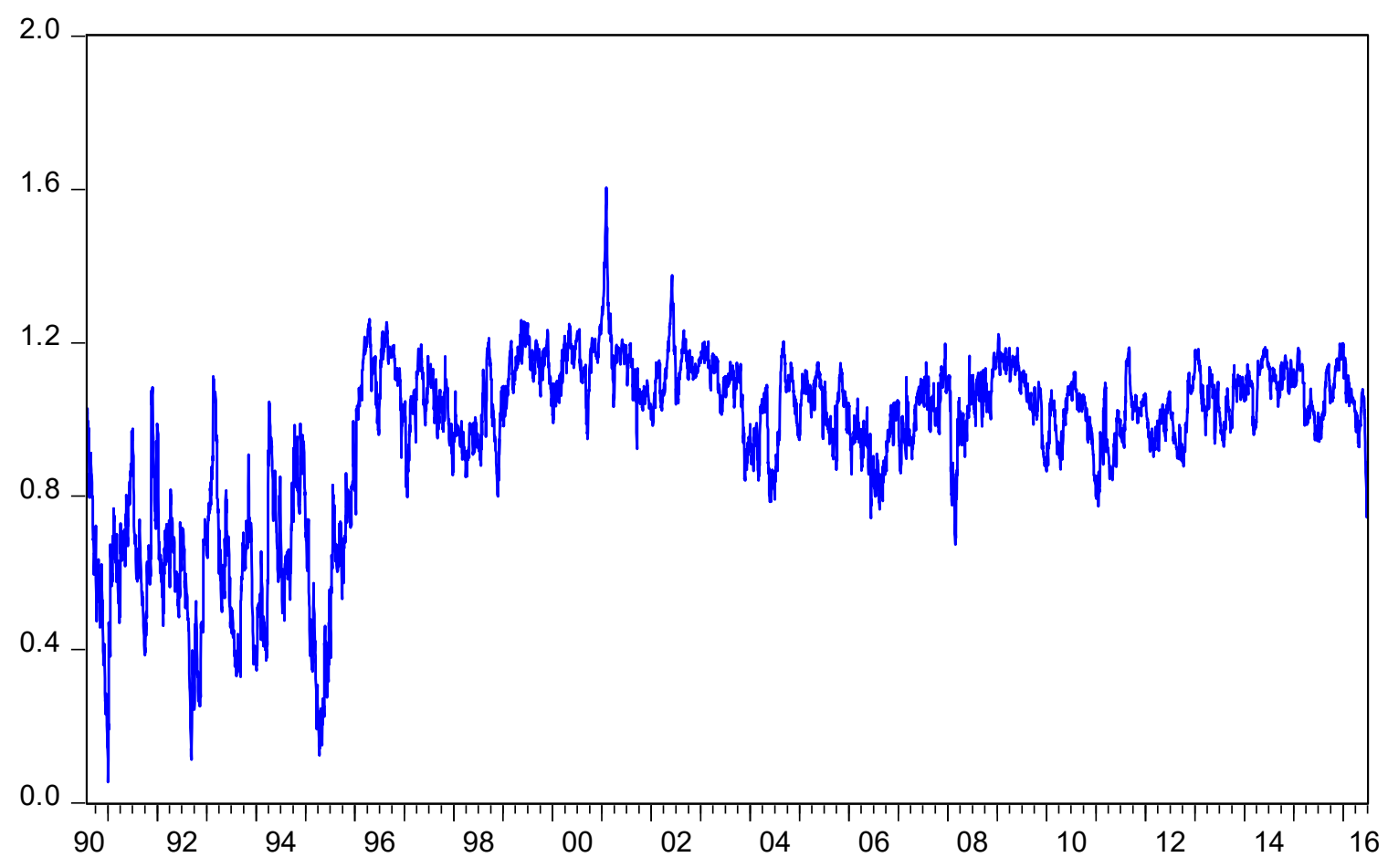

Panel B. Time-varying betas of the European equity portfolio

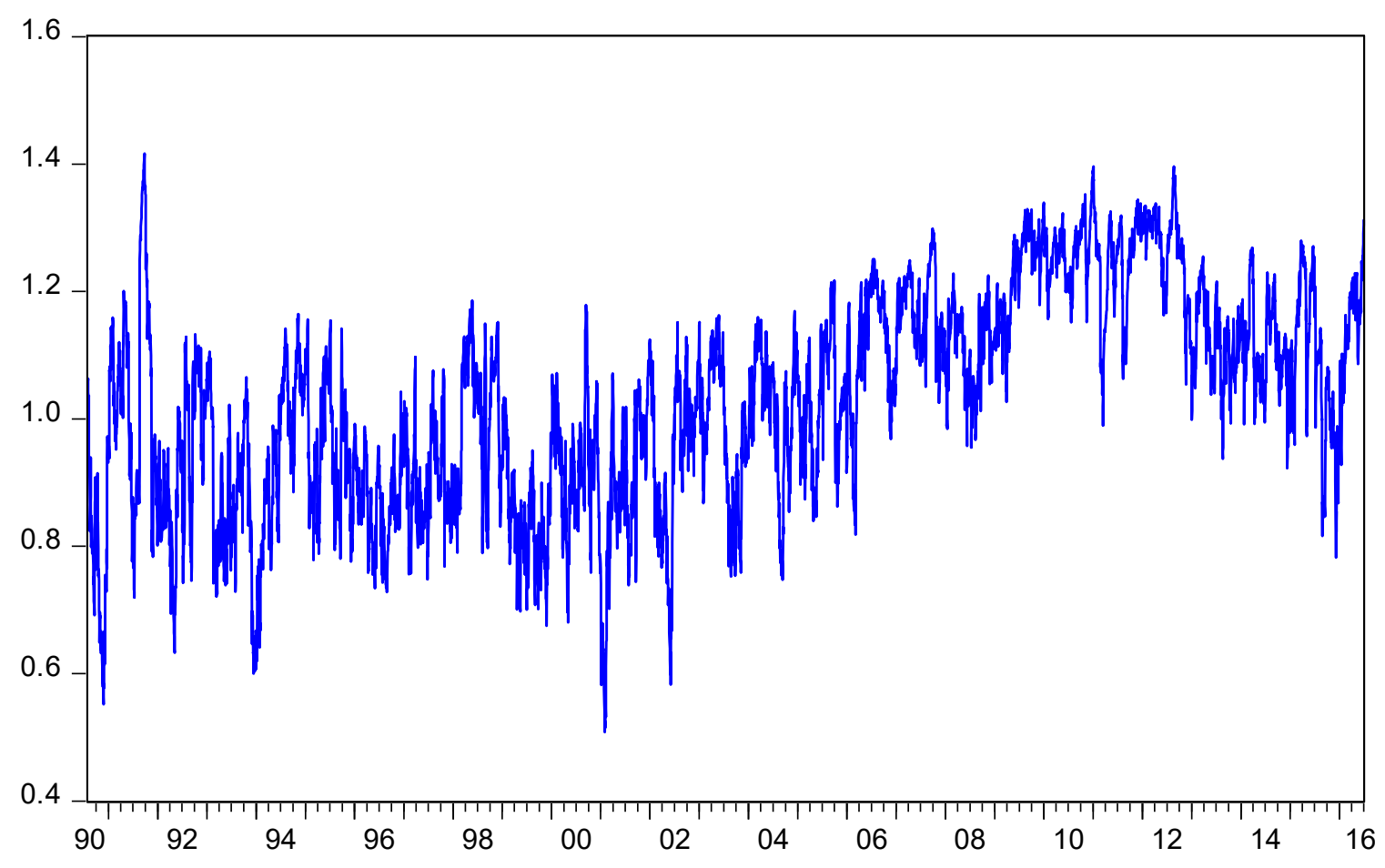

Figure 1. Evolution of the Time-varying Betas of North American and European Equity Portfolio Returns: For the Period from August 1, 1990 to June 30, 2016. 


\section{Conclusions}

This paper investigated the dynamic evolution of the time-varying betas of the international CAPM for North American and European equity portfolio returns over the period from August 1, 1990 to June 30, 2016. Our quantitative studies using the full VECH models revealed the following interesting and useful evidence. First, we found that (1) the time-invariant international CAPM beta value for North American equity portfolio returns and that for European equity portfolio returns, which were derived by the standard OLS method, were both close to one. In contrast, our further investigations found that (2) the time-varying international CAPM betas of North American equity portfolio returns were lower than one before 1996, and slightly higher than one after around 1996. Furthermore, our investigations also revealed that (3) the time-varying international CAPM betas of European equity portfolio returns were lower than one before around 2004; on the other hand, however, they were clearly higher than one after around 2004.

As above, our applications of modern econometric techniques revealed the detailed dynamic evolution of the time-varying international CAPM betas of the North American equity portfolio and the European equity portfolio. We consider that the evidence from our quantitative work is meaningful for understanding the real-world international stock market evolution and linkages. The evidence is considered to be also useful for practical equity investments and actual asset management. Continuing this kind of quantitative research is meaningful and therefore extended this line of research shall be one of our important future tasks.

\section{Acknowledgement}

I am particularly grateful to the repeated kind article invitation from this journal. I also thank the Chuo University Personal Research Grant and the Japan Society for the Promotion of Science Grant-in-Aid for Scientific Research for their generous financial assistance to my research. Moreover, I appreciate anonymous referees for their supportive comments on this paper and I also deeply thank Kenneth French for providing precious time-series data for this research. Finally, I am very much grateful to the Editor, Lucy Xu, for her skilful editorship to my paper and supportive comments on my paper.

\section{References}

Balvers, R. J., \& Klein, A. F. (2014). Currency risk premia and uncovered interest parity in the international CAPM. Journal of International Money and Finance, 41, 214-230. https://doi.org/10.1016/j.jimonfin.2013.12.002

Bollerslev, T., Engle, R. F., \& Wooldridge, J. M. (1988). A capital asset pricing model with time-varying covariances. Journal of Political Economy, 96, 116-131. https://doi.org/10.1086/261527

Hansen, L. P., \& Jagannathan, R. (1997). Assessing specification errors in stochastic discount factor models. Journal of Finance, 52, 557-590. https://doi.org/10.1111/j.1540-6261.1997.tb04813.x 
Jacobsen, B. J., \& Liu, X. (2008). China's segmented stock market: An application of the conditional international capital asset pricing model. Emerging Markets Review, 9, 153-173. https://doi.org/10.1016/j.ememar.2008.06.001

Jan, Y. C., Chou, P. S. R., \& Hung, M. W. (2000). Pacific Basin stock markets and international capital asset pricing. Global Finance Journal, 11, 1-16. https://doi.org/10.1016/S1044-0283(00)00013-2

Solnik, B. H. (1974). An equilibrium model of the international capital market. Journal of Economic Theory, 8, 500-524. https://doi.org/10.1016/0022-0531(74)90024-6

Stulz, R. (1981). A model of international asset pricing. Journal of Financial Economics, 9, 383-406. https://doi.org/10.1016/0304-405X(81)90005-2

Thomas, S. H., \& Wickens, M. R. (1993). An international CAPM for bonds and equities. Journal of International Money and Finance, 12, 390-412. https://doi.org/10.1016/0261-5606(93)90003-T

Tsuji, C. (2012) Positive return premia in Japan. Quantitative Finance, 12, 345-367. https://doi.org/10.1080/14697688.2010.541485

Zhang, X. (2006). Specification tests of international asset pricing models. Journal of International Money and 275-307. https://doi.org/10.1016/j.jimonfin.2005.11.003

\section{Copyright Disclaimer}

Copyright for this article is retained by the author(s), with first publication rights granted to the journal.

This is an open-access article distributed under the terms and conditions of the Creative Commons Attribution license (http://creativecommons.org/licenses/by/3.0/). 